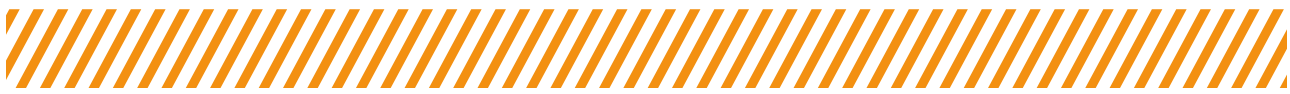

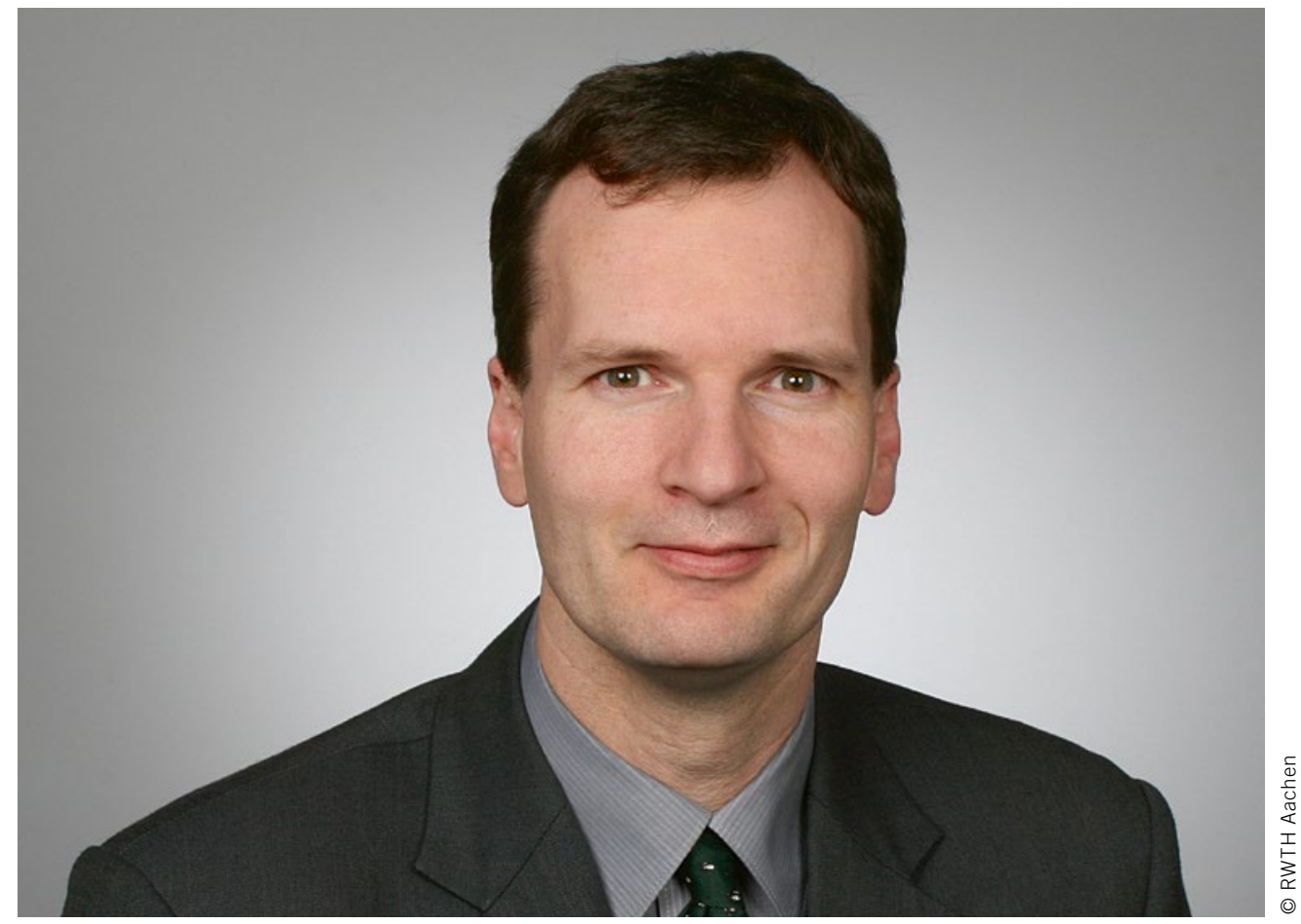

Dr. Dirk Uwe Sauer

Professor für Elektrochemische Energiewandlung und

Speichersystemtechnik an der RWTH Aachen

\section{Nicht auf die nächste Zell-Generation warten}

Zwei Kernkompetenzen werden in Zukunft über den Erfolg im Fahrzeugmarkt entscheiden: Batterietechnik und Technologien zum autonomen Fahren. Wer nicht beide Diziplinen auf höchstem Niveau selbst beherrscht, wird allenfalls ein besserer Zulieferer sein. Daher ist es dringend geboten, wenigstens eine konkurrenzfähige Produktionslinie in Deutschland oder Europa aufzubauen. Die Frage, wie wir dazu kommen können, ist dagegen beliebig kompliziert. Wer finanziert und betreibt eine Fabrik, wer baut die Fabrik, und wie lange wird es dauern, einen wirtschaftlichen Betrieb zu erreichen?

Um Missverständnisse zu vermeiden: Es geht um Zellfertigung mit dem Know-how bei heimischen Firmen. Produktionen asiatischer Zellhersteller sowie die mit Panasonic-Know-how betriebene Giga-Factory von Tesla in den USA werden sicher darüber hinaus ihre Ableger in Europa finden.

Realistisch gesehen wird der Investor in eine Batteriezellfertigung mit eigenem Know-how kein OEM sein. Bis Zellen nach einer Investitionsentscheidung aus der neuen Anlage in Fahrzeugen verbaut werden können, wird es wenigstens fünf, eher sieben Jahre dauern. Wenn die Fertigungsanlagen von europäischen Anlagenbauern bezogen werden, wird eine etwas kleinere Pilotlinie gebaut und eingefahren werden müssen und auf dieser Erfahrungsbasis auf die volle Kapazität hoch skaliert. Dann wird es mindestens 1,5 Jahre dauern, bis eine Fertigung mit hinreichender Qualität und Reprodu- zierbarkeit erreicht wird. Diese Zellen können dann in die Qualifikation bei den OEMs und sicher nicht früher als zwei Jahre danach in der Serienproduktion landen. Betriebe ein OEM die Zellfertigung, müsste er damit rechnen, von seinen bisherigen Lieferanten umgehend vom Know-how und vielleicht auch von Lieferungen ausgeschlossen zu werden. Die Materialhersteller werden auch nicht ihre bestehenden Kunden in Asien verprellen und auf eine eigene Zellfertigung setzen. Bleiben potente Tier 1 oder ein Start-up mit einem großen Finanzier mit langem Atem dahinter. Die zu bauende Fabrik sollte der Größe der Giga-Factory entsprechen und damit etwa 1 bis $2 \%$ der weltweiten Pkw-Produktion mit Batterien beliefern können.

Wenn der Einstieg geschafft werden soll, dann muss das Unternehmen jetzt gestartet werden. Wer auf eine „nächste Generation“ wartet, wird scheitern. Auch auf lange Sicht hin wird die Weiterentwicklung der Zelltechnologie evolutionär sein und weitgehend auf bisherige Produktionstechniken und Anlagen zurückgreifen. Wer bereits in dem Geschäft ist, wird hier immer Vorteile haben. Das Setzen auf eine neue Generation als Startschuss ist ein Märchen, wie das, was noch vor sieben Jahren in Deutschland zu hören war: „Die Asiaten können ja nur Consumer-Batterien, die Anforderungen an Fahrzeugbatterien sind ganz andere, ergo haben sie auch keinen wesentlichen Technologievorsprung.“ 